\title{
inhalt
}

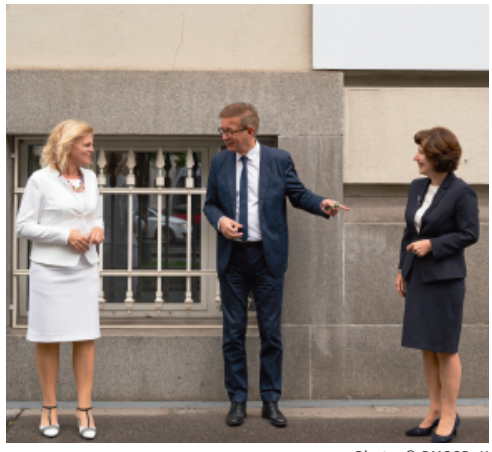

Seite 8

Pflege \& Politik: Gesundheitsminister Rudolf Anschober sieht den ÖGKV als „Partner für die Politik“, denn: „Wir brauchen Sie für fachkompetente Entscheidungen ${ }^{\prime \prime}$

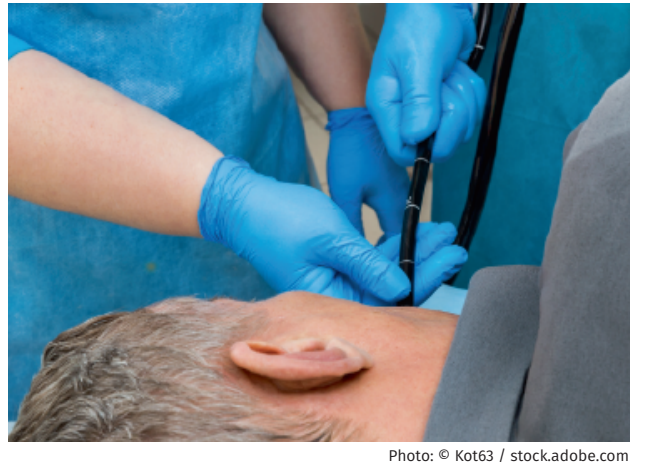

\section{Seite 14}

Checklisten dienen der individuellen Sicherheitskontrolle und sind keinesfalls Tools, die kritisches Mitdenken und Hinterfragen ersetzen. Das gilt auch für den Tätigkeitsbereich der Endoskopie.

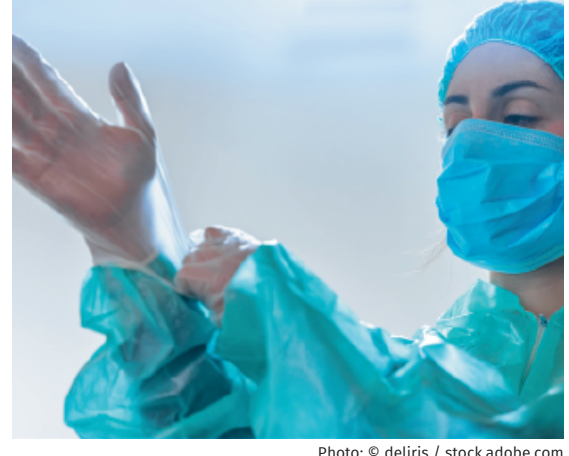

Seite 48

Um gut auf eine mögliche zweite Welle der COVID-19 Pandemie oder andere Pandemien vorbereitet zu sein sollen Gesundheitseinrichtungen frühzeitig mit adäquaten und ausreichenden persönlichen Schutzmaterialien ausgestattet werden.

\section{PFLEGE \& POLITIK}

\section{Neue Rollen und neue} Aufgaben für die Pflege

9 Das 21. Jahrhundert wird das Jahrhundert der Pflege

PFLEGEPRAXIS

10 Ophthalmologiepflege:

Visuelle Halluzinationen

Christian Balon, MSC, Ebendorf/NÖ

14 Endoskopiepflege: Risikomanagement in der Endoskopie

Theresia Schober, Wien

22 Mobile Betreuung: Sehr hohe Zufriedenheit mit der sozialen Alltagsbegleitung

Mag. Doreen Stöhr, MMag. Martina Koller,

Univ.-Prof. Mag. Dr. Hanna Mayer, Wien

PFLEGEKOLLEG

29 Funktionen des Ohrs: Schwindel, Schwerhörigkeit, Gehörlosigkeit

PFLEGE \& WISSENSCHAFT

40 Cochrane Pflege Forum

43 Besuch von Kindern auf der ICU
PFLEGEBILDUNG

44 Online zum „Pflegegipfel des Nordens"; Akkreditierung als Meilenstein

45 Berufsbildende Schule auch für die Pflege; Neue Fachhochschule für die Ostschweiz

46 Gemeinsam beginnen später entscheiden; PflegeDossier: Fortbildung Cannabinoide

PFLegemanAgement

48 Pflege während der COVID-19 Pandemie Dr. Silvia Bauer, MSC, BSC, Dr. Doris Eglseer, MSC, BBSC, Dr. Manuela Hödl, MSC, BSC, Graz

FREIZEIT \& LEBEN

\section{Die wahrscheinlich härteste Segelregatta der Welt; 17. KlezMORE Festival Vienna}

4 Panorama

7 Aktuell: Angst und Unsicherheit prägen den Umgang mit Schizophrenie

20 Aktuell: Die Zeit ist reif für die School Nurse

56 Aktuell: Offene Information verbessert Sicherheit und Lebensqualität

53 Impressum

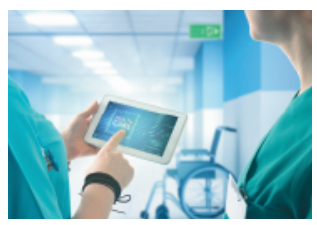

UNSER TITELBILD Digitalisierung und Teamwork sollen die Pflege in die Zukunft führen.

Photo $($ s sefa ozel / Getty Images / istock 